\title{
Custom design of a hanging cooling water power generating system applied to a sensitive cooling water discharge weir in a seaside power plant: A challenging energy scheme
}

\author{
Chuan Min Tian ${ }^{a}$, Mohd Narzam Jaffar ${ }^{b}$, Harunal Rejan Ramji ${ }^{a}$, \\ Mohammad Omar Abdullah ${ }^{\text {a, * }}$ \\ ${ }^{a}$ Faculty of Engineering, Universiti Malaysia Sarawak (UNIMAS), 94300 Kota Samarahan, Sarawak, Malaysia \\ ${ }^{\mathrm{b}}$ Sejingkat Power Corporation Sdn. Bhd. (SPC), Kampung Goebilt, Off Jalan Bako, 93010 Kuching, Sarawak, Malaysia
}

\section{A R T I C L E I N F O}

\section{Article history:}

Received 11 April 2014

Received in revised form

22 December 2014

Accepted 24 December 2014

Available online 24 January 2015

\section{Keywords:}

Critical energy scheme

Exhaust cooling water

Hanging energy recovery system

System efficiency

Techno-economic

\begin{abstract}
A B S T R A C T
In this study, an innovative design of hydro-electricity system was applied to an unconventional site in an attempt to generate electricity from the exhaust cooling water of a coal-fired power plant. Inspired by the idea of micro hydro, present study can be considered new in three aspects: design, resource and site. This system was hung at a cooling water discharge weir, where all sorts of civil work were prohibited and sea water was used as the cooling water. It was designed and fabricated in the university's mechanical workshop and transported to the site for installation. The system was then put into proof run for a threemonth period and achieved some success. Due to safety reasons, on-site testing was prohibited by the power plant authority. Hence, most data was acquired from the proof run. The driving system efficiency was tested in the range of $25 \%$ and $45 \%$ experimentally while modeling results came close to experimental results. Payback period for the system is estimated to be about 4.23 years. Result obtained validates the feasibility of the overall design under the sensitive site application.
\end{abstract}

() 2015 Elsevier Ltd. All rights reserved.

\section{Introduction}

It is true that there is a lack of grid-based electricity supply to remote areas in developing countries and as a consequence, renewable energy technologies such as hydro, solar and wind are to be developed and implemented [1-5]. Broader application of renewable energy technologies contributes substantially towards sustainable economic growth and prominent environmental conservation, though it is common that the intermittent nature of renewable energies has made them comparatively less efficient and economic when operate independently in providing reliable and consistent electricity to consumers [6]. More often than not, a combination of both renewable energy and conventional fuel are found to be the most feasible and practical solution to off-grid electricity, with the conventional fuel complementing the renewable energy [1-3,7]. Most often, there will be many issues associated with different energy schemes and requirements [2,3].

\footnotetext{
* Corresponding author. Tel.: +60 82 583280; fax: +60 82583409.

E-mail addresses: amomar13@gmail.com, amomar@feng.unimas.my (M.O. Abdullah).
}

Evidently, there are rooms for improvements and innovations for renewable energy technologies.

Among various types of renewable energy technologies, micro hydro is deemed as one of the most reliable [4-6,8-10]. Typical micro hydro directly utilizes moving water from stream or river to generate electricity, and in many cases these natural water resources are rather consistent and predictable [6,11]. Considering its consistency and availability which are relatively better than other renewable energies, micro hydro has been widely accepted as the most established and reliable. Its other advantages include zero emission, low maintenance, high durability as well as can be efficiently run by just a few of average local folks. In fact, it has been proven as an effective yet economic solution for off-grid electrification in rural areas $[8,9,11,12]$.

So far it is known that perhaps only drought and winter will affect the water supply, and these factors are relatively gradual and discernible. In the case of these unsteady, torrential rivers having different runoff regimes there is a need to optimize the plant and find the suitable system parameters thus optimized efficiency with shorter investment payback time [13]. Using a mixed-integer nonlinear programming approach, Catalao et al. [14] introduced 